\title{
Sources of organic carbon in fine particulate matter in northern European urban air
}

\author{
S. Saarikoski ${ }^{1}$, H. Timonen ${ }^{1}$, K. Saarnio ${ }^{1}$, M. Aurela ${ }^{1}$, L. Järvi ${ }^{2}$, P. Keronen ${ }^{2}$, V.-M. Kerminen ${ }^{1}$, and R. Hillamo ${ }^{1}$ \\ ${ }^{1}$ Finnish Meteorological Institute, Air Quality, P.O. Box 503, FI-00101 Helsinki, Finland \\ ${ }^{2}$ University of Helsinki, Department of Physics, P.O. Box 64, 00014 University of Helsinki, Finland
}

Received: 11 January 2008 - Published in Atmos. Chem. Phys. Discuss.: 21 April 2008

Revised: 20 August 2008 - Accepted: 17 September 2008 - Published: 29 October 2008

\begin{abstract}
A major fraction of fine particle matter consists of organic carbon (OC) but its origin is still inadequately known. In this study the sources of OC were investigated in the northern European urban environment in Helsinki, Finland. Measurements were carried out over one year and they included both filter $\left(\mathrm{PM}_{1}\right)$ and online methods. From the filter samples OC, elemental carbon (EC), water-soluble OC (WSOC), levoglucosan and major ions were analyzed. Filter data together with the concentrations of inorganic gases were analyzed by Positive matrix factorization (PMF) in order to find the sources of OC (and WSOC) on an annual as well as on a seasonal basis. In order to study the diurnal variation of sources, OC and EC were measured by a semicontinuous OC/EC analyzer and major ions were determined by a Particle-into-Liquid Sampler coupled to ion chromatographs. According to PMF, OC concentrations were impacted by four sources: biomass combustion, traffic, long-range transport and secondary production. On an annual basis the OC concentration was dominated by secondary organic aerosol (SOA). Its contribution to OC was as high as $64 \%$ in summer, which besides anthropogenic sources may also result from the large biogenic volatile organic carbon (VOC) emissions in the boreal region. In winter biomass combustion constituted the largest fraction in OC due to domestic wood combustion for heating purposes. Traffic contributed to OC from 15 to $27 \%$. Regarding the diurnal variation, the contribution from traffic was higher from 08:00 to 18:00 on weekdays than on weekends. The contribution from long-range transport to OC was $24 \%$ on average. All four sources also influenced the WSOC concentrations, however, the contribution of SOA was significantly larger for WSOC than OC.
\end{abstract}

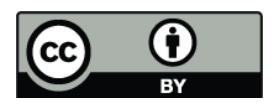

Correspondence to: S. Saarikoski (sanna.saarikoski@fmi.fi)

\section{Introduction}

Urban aerosol is a complex mixture of primary particulate emissions from industry, transportation, power generation and natural sources (e.g. terrestrial dust, volcanic action, sea spray), and of secondary material formed by gas-to-particle conversion mechanisms. A substantial fraction $(20 \%-80 \%)$ of the atmospheric fine particulate matter (PM) in an urban environment consists of carbonaceous material (Nunes and Pio, 1993; Rogge et al., 1993; Sillanpää et al., 2005), but still it is one of the least understood components of aerosols. Carbonaceous material is usually divided in two fractions, elemental carbon (EC, sometimes referred to as black carbon or graphitic carbon) and organic carbon (OC). EC is a primary pollutant formed in combustion processes whereas OC is a complex mixture of many groups of compounds originating from primary sources and secondary formation processes (Seinfeld and Pandis, 1998).

Major anthropogenic emission sources of OC are biomass and fossil fuel combustion. Anthropogenic biomass combustion includes both the agricultural combustion such as burning of biomass for land clearing or new kinds of land use, and the combustion for heat production, e.g. in domestic boilers, wood stoves and fireplaces. The adverse impact of domestic biomass combustion on local ambient air quality is pronounced, because such emissions are mostly unregulated, and the combustion in domestic heating appliances is incomplete (Fine et al., 2002; Glasius et al., 2006). Moreover, the release height of the emissions is typically low, and emissions are highest during the winter when the air mixing can be poor, which both amplify the local air quality impact and increase the risk of adverse health effects in populated areas (Lighty et al., 2000; Naeher et al., 2007). It has been shown that in northern Europe wood combustion can result in local $\mathrm{PM}_{2.5}$ levels comparable to heavily trafficked streets (Glasius et al., 2006). Even though the health effects of traffic related particles have been found to be severe (Kunzli et al.,

Published by Copernicus Publications on behalf of the European Geosciences Union. 
2000; Solomon and Balmes, 2003) there is no reason to assume that health effects of wood combustion are smaller than the health effects of other types of ambient particles (Boman et al., 2003).

In addition to being emitted from motor vehicles and biomass combustion, a large fraction of organic aerosol is formed in the atmosphere from low-volatility compounds produced by the oxidation of gas-phase anthropogenic and biogenic precursors. This secondary organic aerosol (SOA) has been found to contribute to OC from $80 \%$ in summer in Japan (Kondo et al., 2007) to near zero in Pittsburgh, Pennsylvania in winter (Cabada et al., 2002). Recently, it has been stated that there may be a consistent background for SOA in the regional air mass (Subramanian et al., 2007). Also 70\% of primary OC may originate from regional transport instead of local sources.

Concerning the sources of OC, the Helsinki Metropolitan Area is quite special. It is a northern European urban environment located in the boreal region. According to studies (Lindfors et al., 2000) biogenic volatile organic carbon (VOC) emissions, and accordingly biogenic secondary organic aerosol concentrations are outstandingly large in a boreal region (Tunved et al., 2006). Additionally, long-range transport (LRT) has a significant impact on the PM levels in Helsinki, since the mass concentrations due to fine particles from local or regional sources are typically low compared with, e.g., those in Central Europe (Sillanpää et al., 2005). On average 50-75\% of $\mathrm{PM}_{2.5}$ in Finland has been estimated to be long-range transported (Pakkanen et al., 2001; Karppinen et al., 2004) but in the case of OC the influence of LRT is still uncertain. However, it has been shown that during the episodes of long-range transported wild fire emission plumes, the OC concentration increased considerably (Saarikoski et al., 2007).

The aim of this study was to investigate the sources of organic carbon in fine particulate matter in Helsinki, Finland. In a previous study conducted in Helsinki the concentration of OC in fine $\left(\mathrm{PM}_{2.5}\right)$ and coarse $\left(\mathrm{PM}_{2.5--10}\right)$ particles has been explored on an annual basis (Viidanoja et al., 2002). In addition, the sources of $\mathrm{OC}$ in Helsinki, together with five other European cities, have been discussed qualitatively by Sillanpää et al. (2005). However, latter results were limited to a single six-week measurement campaign conducted in Helsinki in springtime. In this study three different approaches were applied in order to investigate the origin of OC. This study together with a paper on the size distributions of water-soluble organic carbon (Timonen et al., 2008) completes significantly the knowledge currently available on the sources and seasonal behaviour of organic aerosol in northern European urban areas.

\section{Experimental}

\subsection{Measurement site}

The measurement site of this study was the urban background station SMEAR III $\left(60^{\circ} 20^{\prime} \mathrm{N}, 24^{\circ} 97^{\prime} \mathrm{E}, 26 \mathrm{~m}\right.$ above sea level) that belongs to the SMEAR network (http://www. atm.helsinki.fi/SMEAR/). The site is situated in the heart of the Helsinki Metropolitan Area, a fairly flat coastal area of the Baltic Sea in Southern Finland. In the city of Helsinki there are 0.5 million inhabitants while the population of the whole area is approximately 1.0 million. The station is located in the campus area of the University of Helsinki at a distance of about $5 \mathrm{~km}$ northeast from the downtown of Helsinki. It is surrounded by the university buildings in the northeastern side, and by mainly forested area, with some buildings in the west. At a distance of less than $200 \mathrm{~m}$ to the east, there is a densely trafficked major road $(60000$ cars/day). The area between this road and the measurement site is forested.

\section{$2.2 \mathrm{PM}_{1}$ filter sampling and analysis}

\subsubsection{Sampling system}

Ambient particulate matter samples were collected using two quartz fiber filters (Whatman Q-MA $47 \mathrm{~mm}$ ) placed in series in a filter cassette system (Gelman Sciences). Prior to the sampling, the quartz filters were cleaned at $550^{\circ} \mathrm{C}$ for six hours. In order to collect the submicrometer particle size fraction of PM only (aerodynamic particle diameter $<1 \mu \mathrm{m}$, $\mathrm{PM}_{1}$ ), the four upper stages (8-11) of the Berner low pressure impactor (BLPI; Berner and Lürzer, 1980) were installed prior to the filter to remove supermicrometer particles. The cut-size of the preimpactor $\left(\mathrm{D}_{50}\right)$ is determined by the lowest stage, the others are used to divide the PM loading to several stages and to ensure removal of particles well above the lowest cut-size. The nominal $\mathrm{D}_{50}$ value for stage 8 is $2 \mu \mathrm{m}$ with a flow rate of $24.5 \mathrm{~L} \mathrm{~min}^{-1}$, but since the flow rate of the BLPI was increased to $80 \mathrm{~L} \mathrm{~min}^{-1}$, the $\mathrm{D}_{50}$ value for the stage 8 decreased to $1 \mu \mathrm{m}$. Calculation was based on the theory presented by Rader and Marple (1985) assuming that the flow is incompressible and the Stokes number is $0.24 . \mathrm{PM}_{1}$ filter samples were collected from the beginning of March 2006 to the end of February 2007. The sampling duration was $24 \mathrm{~h}$ on working days and $72 \mathrm{~h}$ over weekends. The measurement height was $5 \mathrm{~m}$ from the ground surface.

\subsubsection{Chemical analyses}

Pieces with an area of $1 \mathrm{~cm}^{2}$ were punched from the $\mathrm{PM}_{1}$ quartz filters and analyzed for OC, EC, WSOC, levoglucosan and water-soluble ions. Detailed descriptions of the analytical methods have been given by Saarikoski et al. (2007) and 
Timonen et al. (2008). Shortly, OC and EC were determined with a thermal-optical carbon analyzer (Sunset Laboratory Inc., Portland, OR; Birch and Cary, 1996). The temperature program had four steps with the temperatures of $310(90 \mathrm{~s})$, 475 (90 s), 615 (90 s) and $800^{\circ} \mathrm{C}(90 \mathrm{~s})$. In the helium-oxygen phase ( $2 \%$ oxygen) there were six temperature steps: 550 (45 s), 625 (45 s), $700(45 \mathrm{~s}), 775$ (45 s), $850(45 \mathrm{~s})$ and 890 ${ }^{\circ} \mathrm{C}(120 \mathrm{~s})$.

WSOC was analyzed using a Total Carbon Analyzer equipped with a high-sensitive catalyst $\left(\mathrm{TOC}-\mathrm{V}_{\mathrm{CPH}}\right.$, Shimadzu). Samples were extracted by shaking the filter piece with $15 \mathrm{~mL}$ of deionized water (Milli-Q, Gradient, Millipore) for $15 \mathrm{~min}$. The method used was the Non-Purgeable Organic Carbon method, which measured non-volatile OC present in the sample. By acidifying the sample with $1 \%$ acid, inorganic carbon (carbonates, hydrogen carbonates and dissolved carbon dioxide) was eliminated. Water-insoluble organic carbon (WINSOC) was calculated by subtracting the amount of WSOC from that of OC.

Levoglucosan was analyzed with a liquid-chromatograph coupled with an ion trap mass spectrometer (LC-MS; Agilent Technologies, SL). Samples were extracted by using a $2 \mathrm{~mL}$ mixture of tetrahydrofuran and water (1:1) in an ultrasonic bath for $30 \mathrm{~min}$. The LC-MS method was similar to that presented by Dye and Yttri (2005).

Ions were analyzed from the $\mathrm{PM}_{1}$ filter samples using Dionex DX500 or ICS-3000 ion chromatographs (ICs). Prior to analysis samples were extracted with $5 \mathrm{~mL}$ of Milli-Q water, shaken for $10 \mathrm{~min}$ and filtered with IC Acrodisc syringe filters $(0.45 \mu \mathrm{m}$, PALL Gelman Laboratory). DX500 had AG11/CG12A guard columns, AS11/CS12A analytical columns, $500 \mu 1 / 300 \mu 1$ loops, ASRS/CSRS ultra II suppressors and sodium hydroxide/methanesulfonic acid (NaOH/MSA) eluent for anions and cations, respectively. The ICS-3000 setup was similar exceptions of using a different anion column (AS17) and eluent (potassium hydroxide, $\mathrm{KOH}$ ). Nitrate, sulfate, oxalate, ammonium and potassium were obtained from the $\mathrm{PM}_{1}$ samples, whereas other ions usually analyzed by the IC (methanesulfonate, chloride, sodium, magnesium and calcium) could not be determined, either because of the high blanks in quartz filters or because the concentrations were below their detection limits. The detection limits for nitrate, sulfate, oxalate, ammonium, potassium, chloride, sodium, magnesium and calcium were 2.1, $27,2.7,0.035,0.67,0.67,410,3.3$ and $35 \mathrm{ng} \mathrm{m}^{-3}$, respectively, whereas methanesulfonate could not be determined quantitatively because of high background peaks.

Concentrations measured for the back-up filters were subtracted from those of the front filters by assuming that they were only adsorbed gas-phase components of the sample air (positive artifacts) and the adsorption was equal in the front and back-up filters. However, this approach might not be accurate since considering nitrate (data not shown) the average nitrate concentration on the back-up filter was $45 \%$ of that on the front filter, indicating significant evaporation of nitrate from the front filter. Similarly to nitrate also semi-volatile OC could have been volatilized from the front filter (negative artifact) and subsequently collected on the back-up filter. For OC and WSOC the average concentrations of on the backup filter were $12 \%$ and $28 \%$ of the concentrations on the front filter, respectively, whereas for EC, levoglucosan, oxalate, potassium, sulfate and ammonium the corresponding percentages were in the range of $0-4 \%$. It should be noted that the sampling artifacts for OC as well as the OC/EC determination methods are typically unique for each measurement campaign. That makes the accurate comparison between different studies difficult.

\subsection{Online measurements}

\subsubsection{Semicontinuous OC/EC analyzer}

Organic and elemental carbon concentrations were measured using the semi-continuous OC/EC Carbon Aerosol Analyzer (Sunset Laboratory Inc., Portland, OR). Three-hour measurement periods were used to ensure that the concentrations are well above the detection limit even during low concentration events. Measurements started every day at 00:00, 03:17, 06:00, 09:00, 12:00, 15:00, 18:00 and 21:00 local time. The instrument collected particles for 164 minutes (147 min for the measurement started at 03:17) after which the sample was analyzed with the thermal-optical method. At 03:00 a two-minute sample was collected and analyzed similar to the other samples in order to take into account the uncertainties related to the operation of the instrument (instrumental blank). The measurement period for the semicontinuous OC/EC analyzer covered one year, from September 2006 to August 2007.

Similar to the OC/EC analyzer intended to be used in the laboratory (Birch and Cary, 1996), the thermal method of the semicontinuous OC/EC consisted of a helium phase in which OC was determined, and a helium-oxygen phase ( $2 \%$ oxygen) in which EC was determined. The helium phase had two temperature steps: $600^{\circ} \mathrm{C}(80 \mathrm{~s})$ and $840^{\circ} \mathrm{C}(90 \mathrm{~s})$, and the helium-oxygen phase had three steps: $550^{\circ} \mathrm{C}(30 \mathrm{~s}), 650^{\circ} \mathrm{C}$ $(45 \mathrm{~s})$ and $850^{\circ} \mathrm{C}(90 \mathrm{~s})$. Charring of $\mathrm{OC}$ was corrected using the data obtained from the tuned diode laser (red $660 \mathrm{~nm}$ ), which enabled the separation of pyrolyzed OC from EC. The detector in the semicontinuous OC/EC was a non-dispersive infrared detector.

In addition to thermally determined $\mathrm{OC}$ and EC described above, the semicontinuous OC/EC instrument measured optical EC with the laser light transmission $(660 \mathrm{~nm})$. The time resolution for optical EC was three minutes, but the instrument calculated also an average for the selected sampling time. By subtracting optical EC from total carbon (TC; thermal OC + thermal EC) the concentration of so called "optical OC" was obtained. Since the concentrations were low most of the time in Helsinki during this study, the measurements 
Table 1. Annual average concentrations (Annual) and the average concentrations excluding the two major biomass burning episodes (Non-episodic) for the measured particle-phase and gaseous components. OC, EC, WSOC, levoglucosan, ammonium, potassium, sulfate and oxalate were analyzed from the $\mathrm{PM}_{1}$ filter samples.

\begin{tabular}{lrr}
\hline Component & $\begin{array}{r}\text { Annual average } \\
\pm \mathrm{SD}\end{array}$ & $\begin{array}{r}\text { Non-episodic } \\
\text { average } \pm \mathrm{SD}\end{array}$ \\
\hline $\mathrm{OC}\left(\mu \mathrm{g} \mathrm{m}^{-3}\right)$ & $2.5 \pm 2.8$ & $1.5 \pm 0.87$ \\
$\mathrm{EC}\left(\mu \mathrm{g} \mathrm{m}^{-3}\right)$ & $0.89 \pm 0.73$ & $0.74 \pm 0.45$ \\
$\mathrm{WSOC}\left(\mu \mathrm{g} \mathrm{m}^{-3}\right)$ & $1.5 \pm 1.8$ & $0.85 \pm 0.58$ \\
Levoglucosan $\left(\mu \mathrm{g} \mathrm{m}^{-3}\right)$ & $0.064 \pm 0.087$ & $0.041 \pm 0.050$ \\
Ammonium $\left(\mu \mathrm{g} \mathrm{m}^{-3}\right)$ & $0.68 \pm 0.59$ & $0.58 \pm 0.50$ \\
Potassium $\left(\mu \mathrm{g} \mathrm{m}^{-3}\right)$ & $0.072 \pm 0.17$ & $0.057 \pm 0.16$ \\
Sulfate $\left(\mu \mathrm{g} \mathrm{m}^{-3}\right)$ & $1.7 \pm 1.3$ & $1.5 \pm 1.2$ \\
Oxalate $\left(\mu \mathrm{g} \mathrm{m}^{-3}\right)$ & $0.088 \pm 0.096$ & $0.058 \pm 0.053$ \\
$\mathrm{O}_{3}(\mathrm{ppb})$ & $23 \pm 8.9$ & $21 \pm 8.0$ \\
$\mathrm{NO}(\mathrm{ppb})$ & $5.2 \pm 5.9$ & $5.2 \pm 6.1$ \\
$\mathrm{NO}_{2}(\mathrm{ppb})$ & $11 \pm 6.2$ & $11 \pm 5.9$ \\
\hline
\end{tabular}

of TC and optical EC were estimated to be more reliable than those of thermal EC and thermal OC. Therefore only the results of optical EC and "optical-OC" are presented in this paper.

A parallel plate carbon filter denuder (Sunset Laboratory Inc., Portland, OR) was used to remove organic gaseous components from the sample air. The efficiency of the denuder was tested by adding a polytetrafluoroethylene (PTFE) filter to the sampling line prior to the denuder and measuring OC and EC concentrations for 24 hours using a similar procedure to the non-blank measurements. A value of $0.52 \pm 0.10 \mu \mathrm{gC} \mathrm{m}^{-3}$ was measured for the denuder breakthrough. Since the instrumental blank ( 3 minutes sample at 03:00) was equal to $0.36 \pm 0.12 \mu \mathrm{gC}$ sample ${ }^{-1}$, which corresponds to $0.24 \pm 0.079 \mu \mathrm{gC} \mathrm{m}^{-3}$ for a three-hour sample, a value of $0.76 \mu \mathrm{gC} \mathrm{m}^{-3}$ was subtracted from the TC results. That value was $31 \pm 17 \%$ of the measured TC, on average.

The sample flow rate of the semicontinuous OC/EC instrument was originally $5 \mathrm{~L} \mathrm{~min}^{-1}$, but it was raised to $9.2 \mathrm{~L} \mathrm{~min}^{-1}$ in order to increase the sensitivity of the measurements. Also the original cyclone (cut-off at $2.5 \mu \mathrm{m}$ ) was changed to a cyclone with a cut-off at $1 \mu \mathrm{m}$ in order to allow the comparison with the other instruments. The performance of semicontinuous OC/EC analyzer and especially the sampling artifacts have been studied in detail by Arhami et al. (2006).

\subsubsection{PILS-IC}

The ionic composition of fine particles was measured using the Particle-into-Liquid Sampler (PILS; Metrohm Peak Inc; Orsini et al., 2003) coupled with two ion chromatographs.
Prior to the PILS and ICs, a virtual impactor (VI; Loo and Cork, 1988) was used to select an appropriate particle size range. The major flow of the VI $\left(15 \mathrm{~L} \mathrm{~min}^{-1}\right)$ with the fine fraction of aerosols was fed into the PILS system. A VI with a cut-off size of $1.3 \mu \mathrm{m}$ was used. Annular denuders (URG$2000,30 \times 242 \mathrm{~mm}$, Chapel Hill, NC) in a series upstream of the PILS were used to remove acidic gases and ammonia from the sample air. Two denuders were coated with a $\mathrm{KOH}(1 \%)$ solution and one denuder was coated with a phosphoric acid $\left(\mathrm{H}_{3} \mathrm{PO}_{4}\right)(3 \%)$ solution. The samples were analyzed simultaneously using two Dionex ICS-2000 ion chromatographs (Dionex, Sunnyvale, USA). The duration of the IC analysis was 15 minutes, however, it took only $7 \mathrm{~min}$ to fill the IC loop. That means that of 15 minutes time-period 7 min sample was analyzed whereas for 8 minutes the sample flow went to waste. In order to make data handling easier the PILS-IC data was averaged to 15 minutes time- periods following the time-periods of the IC analyses. The PILS-IC system is described in more detailed in Kuokka et al. (2007).

\subsection{Gas-phase components and meteorology}

Ozone $\left(\mathrm{O}_{3}\right)$ was measured using a TEI 49 analyser (Thermo Environmental, Franklin, MA, USA), nitrogen oxides $\left(\mathrm{NO}_{\mathrm{x}}\right)$ using a TEI $42 \mathrm{~S}$ analyzer (Thermo Environmental, Franklin, MA, USA) with molybdenum thermal converter and nitrogen monoxide (NO) using a TEI $42 \mathrm{~S}$ analyzer. Carbon monoxide (CO) was measured using a Horiba APMA 370 analyser (Horiba, Kyoto, Japan), but it operated at SMEAR III only in 2007. Time resolution for the gases was $1 \mathrm{~min}$. Nitrogen dioxide $\left(\mathrm{NO}_{2}\right)$ concentration was calculated by subtracting the NO concentration from that of $\mathrm{NO}_{\mathrm{x}}$. Local meteorological parameters were obtained from the automatic weather station (Vaisala Milos 500, Vaisala Oyj, Vantaa, Finland) that operated next to the measurement site.

\subsection{Data analysis}

In order to study the sources of organic carbon, a Positive matrix factorization (PMF) method was used. PMF is a least-squares-based factor analysis model that has been used in various studies to identify the sources of particles (e.g., Huang et al., 2006; Song et al., 2006). The PMF method has been described in detail by Paatero $(1997,1999)$. The episodic samples (two major biomass burning episodes) were excluded from the data set, after which the data consisted of 230 samples and 11 variables. PMF was run with the factor numbers of 3-6 giving the best fit for four factors. The factor solution explained $88-100 \%$ of the variation of each component, with the lowest percentage obtained for ozone. The uncertainties used for the PMF analysis were in the range of $5-15 \%$, the lowest percentage being estimated for sulfate and the largest for WSOC and levoglucosan. 


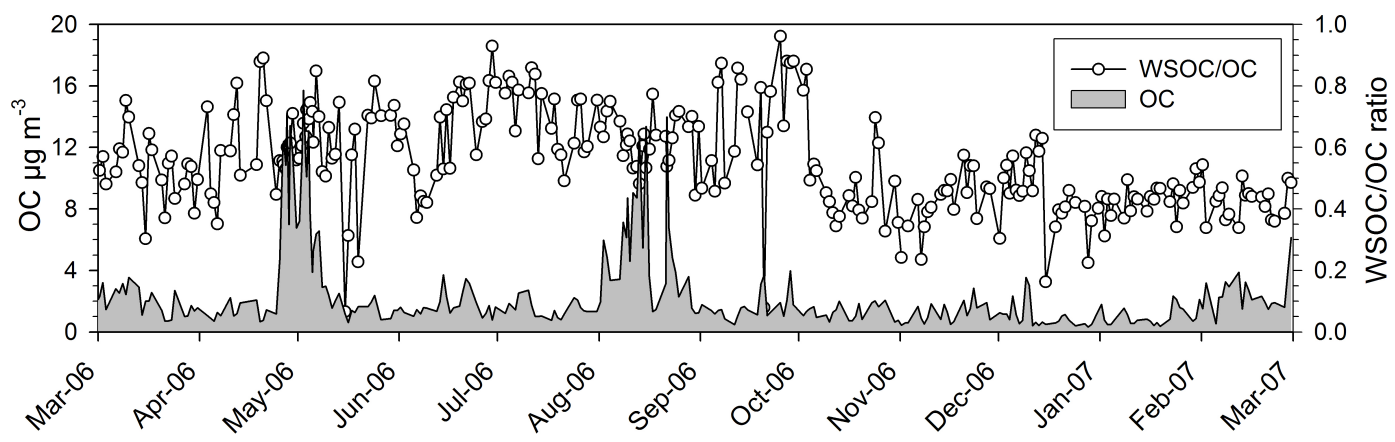

Fig. 1. OC concentration and the WSOC/OC ratio from March 2006 to February 2007 at SMEAR III in Helsinki. OC and WSOC were analyzed from the daily $\mathrm{PM}_{1}$ filter samples.

For OC and WSOC the concentrations associated with each source (factor) were calculated by multiplying the concentration of $\mathrm{OC}$ by the relative contribution of each source $(0-1)$ and by the fraction of OC $(0-1)$ attributed to each source.

\section{Results and discussion}

\section{1 $\mathrm{PM}_{1}$ filter measurements}

\subsubsection{Annual concentrations}

The $\mathrm{PM}_{1}$ filter measurements were carried out from March 2006 to February 2007. During that time there were two major episodes when smoke from biomass burning was intercepted. The first episode in April-May 2006 was long-range transported and during that episode the concentrations were continuously elevated over 12 days (Saarikoski et al., 2007). The second episode in August 2006 was a series of shortterm concentration peaks of which most originated from forest fires that were in Russia only $150-200 \mathrm{~km}$ from the measurement site.

The annual-average concentration of $\mathrm{OC}$ was equal to $2.5 \mu \mathrm{g} \mathrm{m}^{-3}$ (Table 1). As it can be seen from Fig. 1, the OC concentration elevated significantly during the biomass burning episodes, which raised the annual-average. By excluding the biomass burning episodes, the average OC concentration became equal to $1.5 \mu \mathrm{g} \mathrm{m}^{-3}$. It was clearly lower than the annual-average OC measured by Viidanoja et al. (2002) between July 2000 and July 2001 in Helsinki $\left(3.0 \mu \mathrm{g} \mathrm{m}^{-3}\right)$, but also the average for EC was higher in their study $\left(1.2 \mu \mathrm{g} \mathrm{m}^{-3}\right)$ than in this paper (Table 1$)$. In addition to the apparent year-to-year variation, the difference was probably caused by the different location of the measurement sites. Viidanoja et al. (2002) measured very close to a road $(14 \mathrm{~m})$, whereas in this study the site was not directly influenced by the traffic. Additionally, the site used in this study was located on top of a small hill, which enabled higher wind speeds and therefore more efficient dilution of local emis-

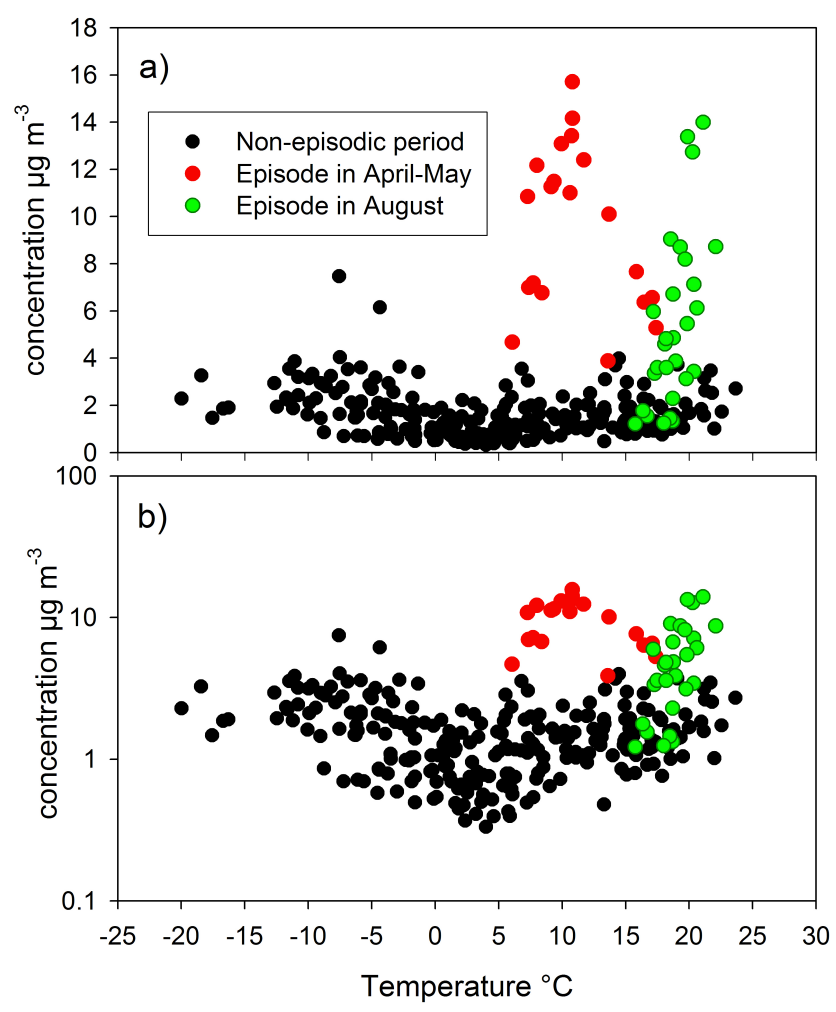

Fig. 2. The concentration of OC plotted against ambient temperature in linear (a) and in logarithmic scale (b). Two biomass burning episodes are shown separately. Results are from the $\mathrm{PM}_{1}$ filter samples collected on a daily basis.

sions. Also the measured size fractions were slightly different. In the work of Viidanoja et al. (2002) the collected size fraction was $\mathrm{PM}_{2.5}$ and in this work it was $\mathrm{PM}_{1}$.

The annual-average contribution of WSOC to OC was $56 \%$. By taking into account the large variability of this contribution during the year, the split between WSOC and WINSOC during the biomass burning episodes was not different from that during other times of the year (Fig. 1). The annual average concentration of sulfate was $1.7 \mu \mathrm{g} \mathrm{m}^{-3}$ with 

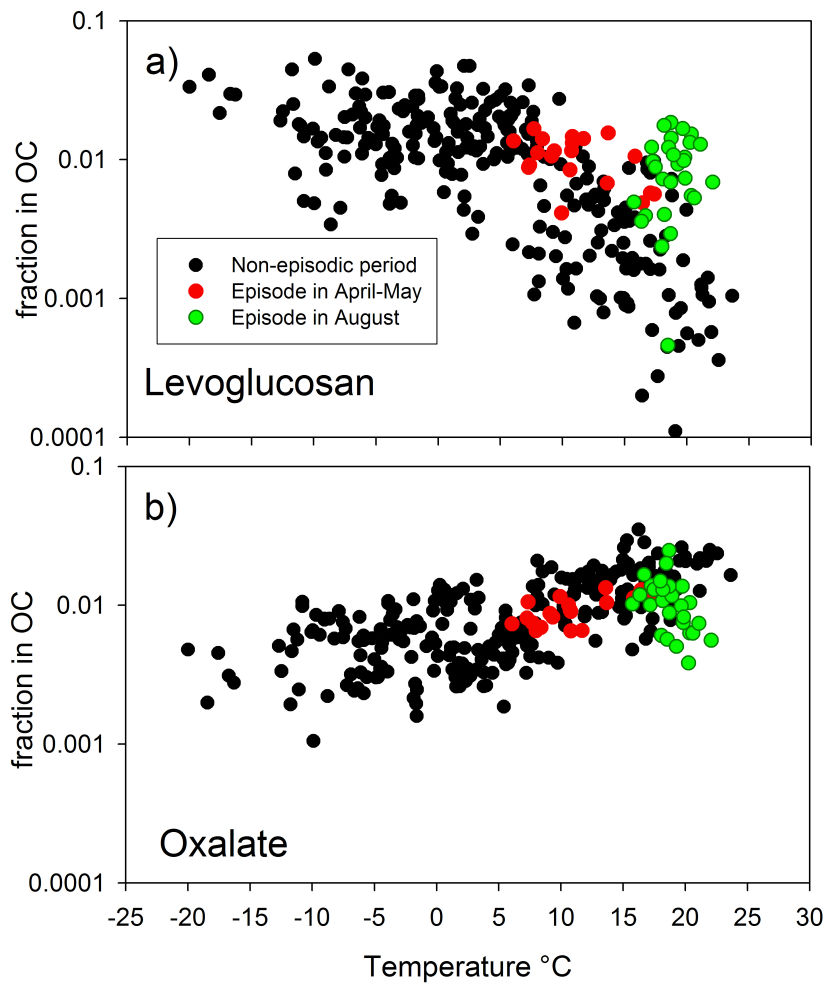

Fig. 3. The fraction of carbon associated with levoglucosan (a) and oxalate (b) in OC plotted against ambient temperature. The biomass burning episodes in April-May and in August are shown separately. Note logarithmic y-axis. Levoglucosan, oxalate and OC were analyzed from the $\mathrm{PM}_{1}$ filter samples.

no clear difference between the annual and non-episodic average concentrations (Table 1). Also for ammonium the nonepisodic average was only slightly smaller than the annual average including the episodes.

\subsubsection{Seasonal variation}

OC concentrations had a slight dependence on ambient temperature. The $\mathrm{OC}$ concentration decreased with the increasing temperature up to about $4^{\circ} \mathrm{C}$, whereas above $4^{\circ} \mathrm{C}$ the OC concentration increased with the increasing temperature (Fig. 2). Since the biomass burning (wildfire) episodes clearly deviated from the seasonal trend, they are shown separately. The WSOC concentration showed a pattern similar to that of $\mathrm{OC}$ when plotted against the ambient temperature, which is expected since WSOC correlated strongly with OC (Pearson correlation coefficient, R, 0.84). However, there seems to be a seasonal trend for the fraction of WSOC in $\mathrm{OC}$, since the WSOC/OC ratio dropped in the beginning of October 2006 and stayed at a lower level until the end of the measurement period (Fig. 1). The measured meteorological parameters (T, RH, wind speed and direction) could not explain the change in the WSOC/OC ratio. The decrease of the WSOC/OC ratio in fall agrees with the previous studies con- ducted in Europe (Decesari et al., 2001; Jaffrezo et al., 2005; Viana et al., 2007), in which a slightly larger WSOC fraction has been measured in summer than in winter. The seasonal variation of the WSOC fraction indicates that the sources, or source contributions, are different for WSOC and OC. Some evidences for this will be presented in Sect. 3.1.3. The temperature is a good parameter for examining the seasonal cycles of PM in Finland where there are four clear seasons with different temperature profiles. Nevertheless, the temperature is not independent of other variables such as the global radiation.

The temperature dependence of OC (and WSOC) can be explained by two major sources that depend on the season. First, by using levoglucosan, which is a tracer for biomass combustion (Simoneit et al., 1999), it is possible to track wood combustion in the residential heating. The annualaverage levoglucosan concentration was $0.064 \mu \mathrm{g} \mathrm{m}^{-3}$ (Table 1) with a large temporal variability and clearly higher concentrations measured in winter than in summer. The same trend was found when the carbon content of levoglucosan was compared to OC (Fig. 3a). The fraction was quite stable at temperatures below $5^{\circ} \mathrm{C}$ but decreased steeply with increasing temperature above $5^{\circ} \mathrm{C}$. This indicates that the domestic wood combustion is a significant source of $\mathrm{OC}$ at low temperatures (in winter), but it may also imply that levoglucosan is not stable in the atmosphere in summer. This topic will be discussed in more detail in Sect. 3.1.4.

Oxalate has several sources, including engine exhaust emissions, fuel oil combustion, biomass burning and biogenic sources (Chebbi and Carlier, 1996). Most of these sources are secondary. The fraction of oxalate in $\mathrm{OC}$ is plotted against temperature in Fig. 3b. The observed pattern for oxalate was opposite to for levoglucosan, showing an increasing fraction with the increasing ambient temperature. However, for temperatures below $0^{\circ} \mathrm{C}$ the fraction of oxalate in OC did not correlate with temperature. This finding agrees with the observation made in the French Alps (Jaffrezo et al., 2005), in which the fraction of dicarboxylic acids in WSOC increased with increasing temperature. However, the threshold temperature was different between the two sites in the Alps $\left(7\right.$ and $\left.4^{\circ} \mathrm{C}\right)$ and this study (approx. $\left.0^{\circ} \mathrm{C}\right)$. Jaffrezo et al. (2005) suggested that there are two regimes for the formation of WSOC: at warmer temperatures the formation is related closely to oxidation processes producing dicarboxylic acids, whereas at lower temperatures the formation of WSOC is more loosely dependent upon the formation of dicarboxylic acids.

\subsubsection{Sources of OC by PMF}

In addition to studying the sources of $\mathrm{OC}$ by means of seasonal variation, they were investigated by using the PMF method. PMF yielded four factors (Fig. 4), of which two were similar to those found in the previous section. The first factor had a large contribution from oxalate $(63 \%)$ 

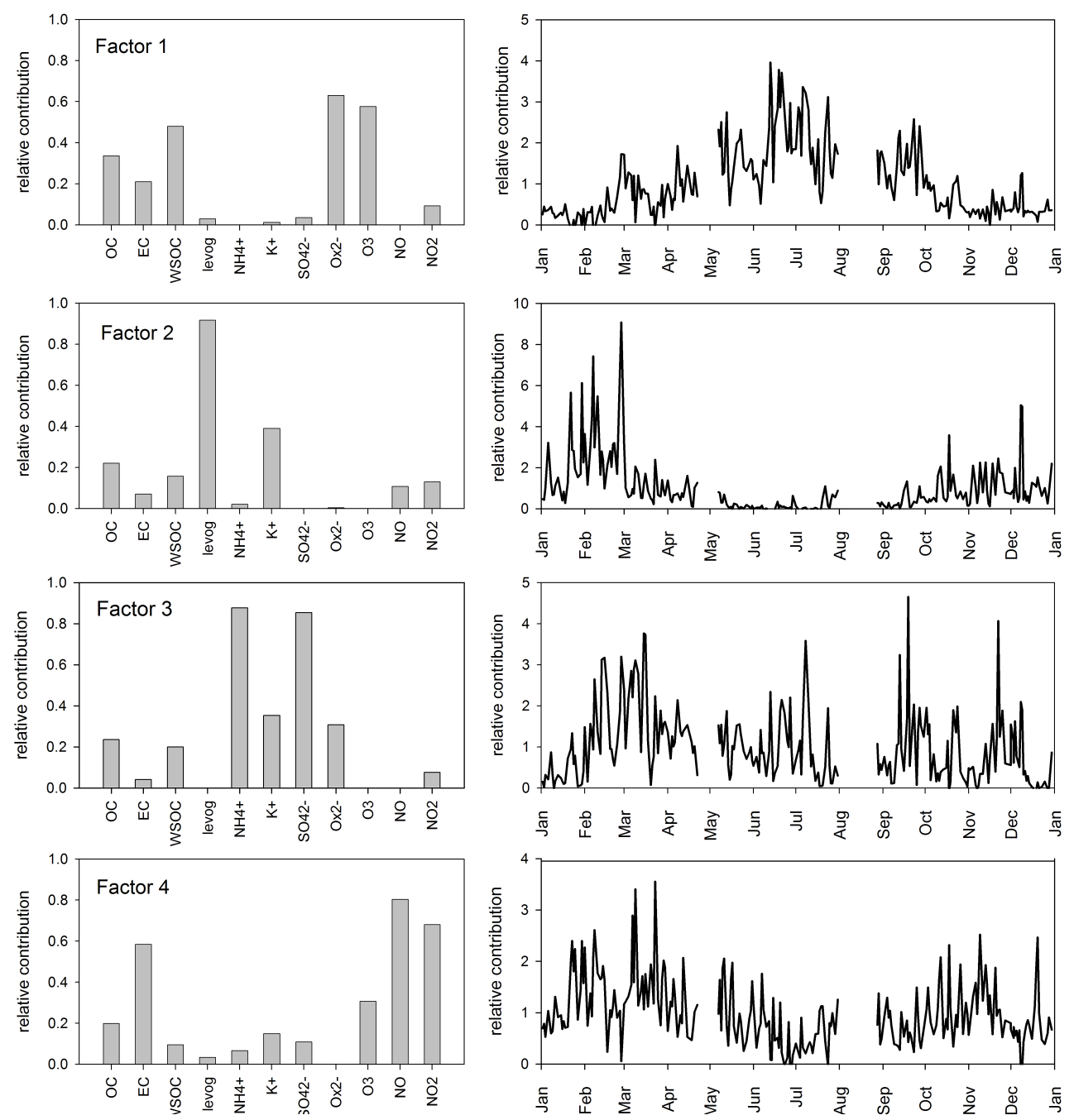

Fig. 4. The composition of four factors resolved by PMF (left column) and their time series (right column). Factors were identified as secondary organic aerosol (factor 1), biomass combustion (factor 2), long-range transport (factor 3) and traffic (factor 4). The number of $\mathrm{PM}_{1}$ filter samples was 230 since two major biomass burning episodes were excluded from the data set.

and ozone (58\%), suggesting that this factor represents secondary organic aerosol. The second factor was identified as biomass combustion because nearly all levoglucosan (92\%) was loaded into this factor. Also a large fraction (39\%) of potassium, another tracer for biomass combustion, was associated with the second factor, whereas almost an equal contribution $(35 \%)$ of potassium was loaded into the third factor. Due to high loadings of sulfate $(88 \%)$ and ammonium $(85 \%)$ the third factor was identified as long-range transport. The large contribution of potassium associated with this factor suggests that in addition to secondary inorganic ions, the LRT aerosol was also composed of biomass combustion emissions. The fourth factor was influenced by traffic-related components $\mathrm{EC}, \mathrm{NO}$ and $\mathrm{NO}_{2}$ with the percentages associated with this factor equal to $58,80,68 \%$, respectively. Biomass combustion and traffic can be assumed to be pri- mary sources for OC, whereas LRT was a mixture of components originating from primary and secondary sources. Other primary sources of OC, like cooking emissions, coke production, vegetative detritus and cigarette smoke (Subramanian et al., 2007), could not be extracted from the data because the molecular markers for those sources were not analyzed. However, the contribution of those sources can be assumed to be small in Helsinki. Due to the uncertainties in the sampling the sources of the OC were assessed in the conditions of the experiment, which might not be exactly the same as ambient particulate OC.

The seasonal variation of the four resolved factors is shown in Fig. 4 (right panel). Prior to PMF the biomass burning episodes were removed from the data set, since the source profiles during the episodes are likely to be different from those during the non-episodic period, and since the 

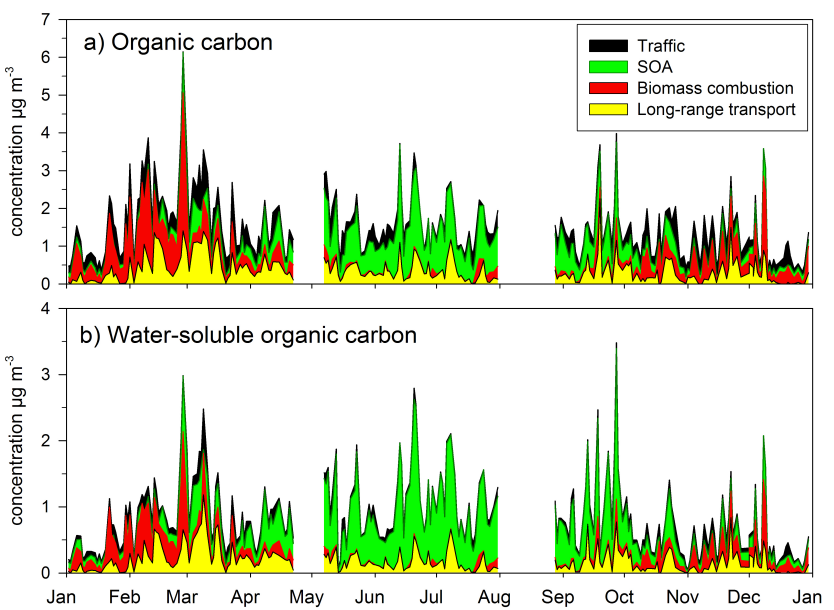

Fig. 5. The concentrations of the four OC fractions (a) and WSOC fractions (b) attributed to the sources identified by PMF. Samples were $\mathrm{PM}_{1}$ filter samples.

focus of this study was on the sources generally influencing Helsinki. That resulted in two gaps in the time-series, one in April-May and the second in August.

On an annual-basis OC was associated mostly with secondary organic aerosol (34\%), whereas the rest of OC was distributed equally among the three other factors. Regarding water-soluble $\mathrm{OC}$ even a larger fraction was attributed to secondary organic aerosol $(48 \%)$. That agrees with the earlier results obtained in Tokyo, in which most of WSOC was found to originate from secondary organic aerosol formation (Kondo et al., 2007). The impact of LRT and biomass combustion was slightly smaller on WSOC than on OC, whereas the influence of traffic was significantly larger on OC than on WSOC. Although vehicle emissions are found to be linked to WSOC (Sullivan et al., 2006) the contribution of traffic to WSOC was only $9.5 \%$.

The OC concentrations attributed to the four sources are presented in Fig. 5a. As expected, in winter months most of the OC was associated with biomass combustion (41\%, Table 2). Although there were day-to-day variations in the concentration of OC in winter, the contribution of biomass combustion was quite stable, indicating continuous biomass combustion for residential heating in winter in Helsinki. The contribution of biomass combustion in Helsinki was close to that measured in Zurich, Switzerland, (41\%; Szidat et al., 2006) and that observed in Ghent, Belgium, (35\%; Zdráhal et al., 2002) in winter. In Zurich and Ghent, however, the studied size fraction was $\mathrm{PM}_{10}$. In Pittsburgh, Pennsylvania, the impact of biomass combustion on OC $\left(\mathrm{PM}_{2.5}\right)$ was significantly smaller, only $10 \%$ in winter (Robinson et al., 2006b).

A significant seasonal variation was also found for the contribution of secondary organic aerosol. The contribution of SOA to OC increased from spring to summer and decreased from summer to fall and winter (Fig. 5a). Excluding winter, SOA was a major fraction of OC with the seasonal-average contribution ranging from $32 \%$ in fall to $64 \%$ in summer (Table 2). The contribution of SOA was lower in Helsinki in summer than that determined in Tokyo, Japan, where $81 \%$ of organic aerosol was found to be from SOA in summer (Kondo et al., 2007), but much higher than that measured in Pittsburgh where $38 \%$ of OC was calculated to be SOA in summer (Polidori et al., 2006). In Zurich, $60 \%$ of OC $\left(\mathrm{PM}_{10}\right)$ in summer and $27 \%$ in winter were attributed to biogenic emissions, of which the majority was stated to be SOA (Szidat et al., 2006).

The contribution of traffic to OC varied notably from day to day, but the seasonal-average contributions were quite stable ranging from 25 to $27 \%$ (Table 2), except in summer. In summer the traffic-related OC was only 15\% (Table 2) probably because of low traffic volume during summer holidays. The contribution of traffic to OC was slightly larger in Helsinki than in Toronto, Canada, where $10-20 \%$ of OC was due to primary particulate OC emissions from motor vehicles with the lack of a seasonal pattern (Brook et al., 2007). In Pittsburgh vehicular contribution to OC was found to be between 13 and 20\% in winter (Subramanian et al., 2006).

The contribution of long-range transport to OC was highest in spring (29\%) and somewhat lower ( $20 \%)$ during the other seasons (Table 2). However, in addition to spring also in summer and in fall most of the OC concentration peaks were due to the high contribution of LRT (Fig. 5a). In winter all high OC concentrations were caused by the large contribution of biomass combustion.

Regarding the source contributions of WSOC, the seasonal variation was similar to that found for $\mathrm{OC}$, except that the fraction of SOA was more pronounced throughout the year (Fig. 5b). The seasonal variation of SOA explains the drop in the WSOC/OC ratio observed in October 2006 (Fig. 1). Since most of WSOC is attributed to SOA, the decrease in SOA formation in October lowered the WSOC concentrations. For OC concentration there was no significant change in October because the contribution of biomass combustion OC increases concurrently with the decreasing contribution of SOA (Fig. 5a). The influence of biomass combustion was smaller on WSOC than on OC. However, in Shenzhen (China) biomass burning has been found to be the major source of WSOC both in winter and summer (Huang et al., 2006), the contributions ( $76 \%$ in winter and $58 \%$ in summer) being much higher than those measured in Helsinki in this study (Table 2)..

\subsubsection{Characterization of sources}

The OC/EC and WSOC/OC ratios calculated for the four sources are shown in Table 3. Of these sources, the OC/EC ratio was smallest for traffic. For traffic the ratio obtained in this study (0.71) was smaller than those given for light duty gasoline vehicles (2.2) and for heavy-duty diesel vehicles $(0.8)$ by Na et al. (2004). The fraction of WSOC in OC was only $27 \%$ for traffic but it is still twice the percentage 
Table 2. The source contributions for OC and WSOC in winter (December-February), spring (March-May), summer (June-August) and fall (September-November) (average \pm SD). Sources and their contributions were identified by PMF.

\begin{tabular}{llrrrr}
\hline & & Winter & Spring & Summer & Fall \\
\hline \% of OC & Secondary organic aerosol & $16 \pm 11$ & $34 \pm 17$ & $64 \pm 12$ & $32 \pm 18$ \\
& Biomass combustion & $41 \pm 15$ & $12 \pm 8.9$ & $3.4 \pm 6.0$ & $20 \pm 14$ \\
& Long-range transport & $17 \pm 13$ & $29 \pm 10$ & $19 \pm 11$ & $21 \pm 14$ \\
& Traffic & $26 \pm 12$ & $25 \pm 13$ & $15 \pm 13$ & $27 \pm 15$ \\
& Sef WSOC & $28 \pm 18$ & $49 \pm 19$ & $78 \pm 8.8$ & $47 \pm 21$ \\
& Biomass combustion & $38 \pm 16$ & $11 \pm 8.1$ & $2.3 \pm 4.1$ & $18 \pm 15$ \\
& Long-range transport & $18 \pm 14$ & $27 \pm 11$ & $13 \pm 8.4$ & $20 \pm 13$ \\
& Traffic & $16 \pm 8.5$ & $14 \pm 9.0$ & $6.6 \pm 6.7$ & $15 \pm 11$ \\
\hline
\end{tabular}

measured close to a high traffic road in Paris, France (12.5\%, Ruellan and Cachier, 2001).

Traffic seemed to be a source of SOA as well, indicated by a relatively small OC/EC ratio obtained for SOA (Table 3). In addition to traffic also biogenic production is supposed to be a major source for SOA because in the boreal region biogenic secondary organic aerosol concentrations are high (Tunved et al., 2006). Although the measurements discussed in this paper were made in an urban background area, biogenic SOA is likely to be important because it has been suggested that there is a consistent background for SOA in the regional air (Subramanian et al., 2007), and that anthropogenic species play a role in SOA formation from biogenic VOCs (Weber et al., 2007). Also for the urban environment of Zurich, it has been estimated that biogenic SOA exceeds anthropogenic SOA in summer (Szidat et al., 2006). The contribution of biogenic SOA is not limited to summertime, since in Zurich biogenic emissions were found to be a significant source of OC even in winter. However, in Helsinki the biogenic VOC emissions can be assumed to be smaller than in Zurich in winter since the growing season is much shorter in Helsinki than in Zurich. Nearly all (80\%) secondary organic aerosol was water-soluble, which is in line with the statement that WSOC is the major constituent of secondary organic aerosol (Saxena and Hildemann, 1996).

The largest OC/EC ratio (12, Table 3) was obtained for the long-range transport. It is clearly larger than the corresponding ratio measured in Amsterdam, Barcelona and Ghent (4.4-8.9) during the periods when aerosols were of regional or long-range continental origin (Viana et al., 2007). The WSOC/OC ratio was 0.47 for LRT, which was lower than expected since transport allows for more photochemical processing of aerosol leading to more oxidized and therefore more water-soluble OC. However, the WSOC/OC ratio was larger for LRT than for the fresh emission sources, traffic (0.27) and biomass combustion (0.40). The WSOC/OC ratio for LRT was also larger than that measured by Viana et al. (2007) in Amsterdam (0.34) and Barcelona (0.36) when aerosols had regional or long-range continental European origin.
Table 3. OC/EC, WSOC/OC and OC/levoglucosan ratios for the four identified sources.

\begin{tabular}{lrrrr}
\hline & $\begin{array}{r}\text { Secondary } \\
\text { organic } \\
\text { carbon }\end{array}$ & $\begin{array}{r}\text { Biomass } \\
\text { combustion }\end{array}$ & $\begin{array}{r}\text { Long- } \\
\text { range } \\
\text { transport }\end{array}$ & Traffic \\
\hline OC/EC & 3.3 & 6.6 & 12 & 0.71 \\
WSOC/OC & 0.80 & 0.40 & 0.47 & 0.27 \\
OC/levoglucosan & & 9.2 & & \\
\hline
\end{tabular}

For biomass combustion the OC/EC ratio was equal to 6.6. This ratio is higher than that obtained by Frey et al. (2006) for smoldering (2.4) and normal combustion (0.93) in laboratory tests carried out in Finland. Frey et al. (2006) burned only one wood species, birch, which is the most common wood in small-scale residential heating. For other wood species used in Finland, spruce and pine, OC/EC ratios from 1.7 to 2.5 have been measured (Iinuma et al., 2007). In contrast, the OC/EC ratio obtained in this study is much lower than the average OC/EC ratio Fine et al. $(2001,2002,2004)$ measured for 22 wood species (26). $40 \%$ of OC attributed to biomass combustion was water-soluble (Table 3 ). Compared to laboratory studies of Frey et al. (2006), the percentage was two times that measured for normal and smoldering combustion (22\% and $18 \%$, respectively) but it was only slightly higher than that obtained by Iinuma et al. (2007) (29 to 38\%). It is obvious that a large portion of water-insoluble OC emissions from biomass combustion transform into water-soluble OC through oxidation in the atmosphere. However, that process must be quite fast since the particulate matter from the biomass combustion measured in this study is assumed to be regional or to a certain extent even local.

The OC/levoglucosan ratio has been used in order to assess the contribution of biomass combustion related OC to total OC measured from the ambient air (e.g. Zdráhal et al., 2002). According to the PMF results the OC/levoglucosan ratio was 9.2 for biomass combustion (Table 3 ). It is slightly smaller than the ratio measured by Frey et al. (2006) for normal combustion (9.8) but in the case of smoldering the ratio 


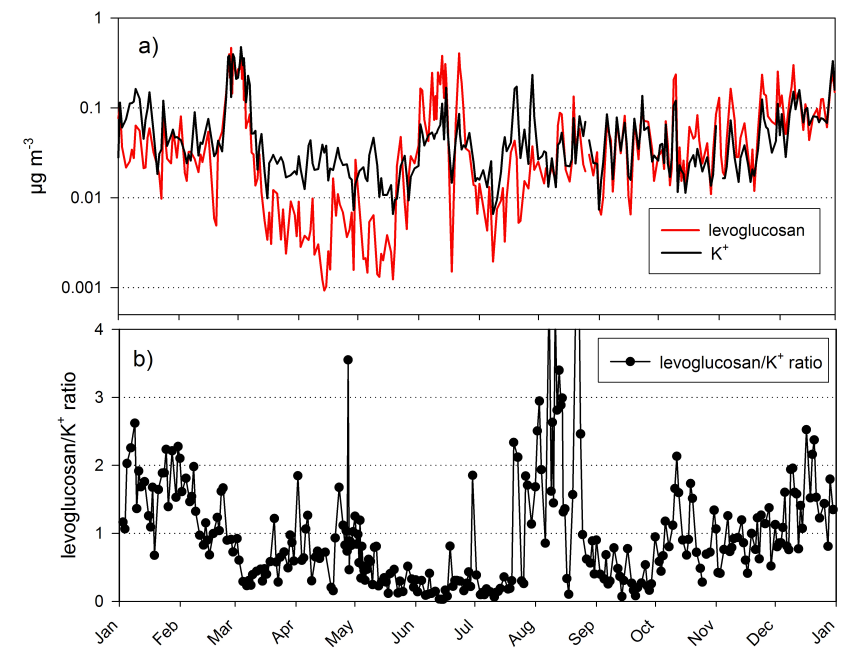

Fig. 6. Time trend for the concentrations of levoglucosan and potassium (a) and for the levoglucosan/potassium ratio (b). Note in logarithmic scale for $y$-axis in (a). Levoglucosan and potassium were analyzed from the $\mathrm{PM}_{1}$ filter samples.

was significantly higher being equal to 24.6. In the studies of Fine et al. $(2001,2002,2004)$ the average OC/levoglucosan ratio was 14.2 but the variation between the wood species was substantial ranging from 3.0 to 100 . A rather small OC/levoglucosan ratio has been measured for pine (2.1-3.5) and spruce (2.1) by Iinuma et al. (2007).

The suitability of levoglucosan for quantitatively tracking the biomass combustion emissions can be questioned, since its emission fraction is highly dependent on combustion conditions (Hedberg et al., 2006). Congruent with this, also the ambient ratios of different biomass smoke markers have been found to vary significantly from day to day, indicating that the composition of the biomass smoke is variant (Robinson et al., 2006b). Also the sampling methods as well as the correction methods for the sampling artifacts (negative and positive) affect the OC/levoglucosan ratios measured either for the biomass combustion aerosol or for the ambient aerosol samples.

Laboratory tests have shown that levoglucosan is stable over a period of 10 days (Fraser and Lakshmanan, 2000). However, Gao et al. (2003) speculated that levoglucosan may be chemically converted into diacids during an upward transport. In this study also evidence for the depletion of levoglucosan was found. Figure 6 shows the time trends for the concentrations of levoglucosan and potassium (Fig. 6a) as well as the levoglucosan/potassium ratio (Fig. 6b). The concentration of levoglucosan decreased more sharply than that of potassium from winter to summer. By assuming that they both originated only from biomass combustion it must be levoglucosan that had disappeared from the particles since potassium is known to be stable in the atmosphere. In summer levoglucosan may have been photochemically oxidized.

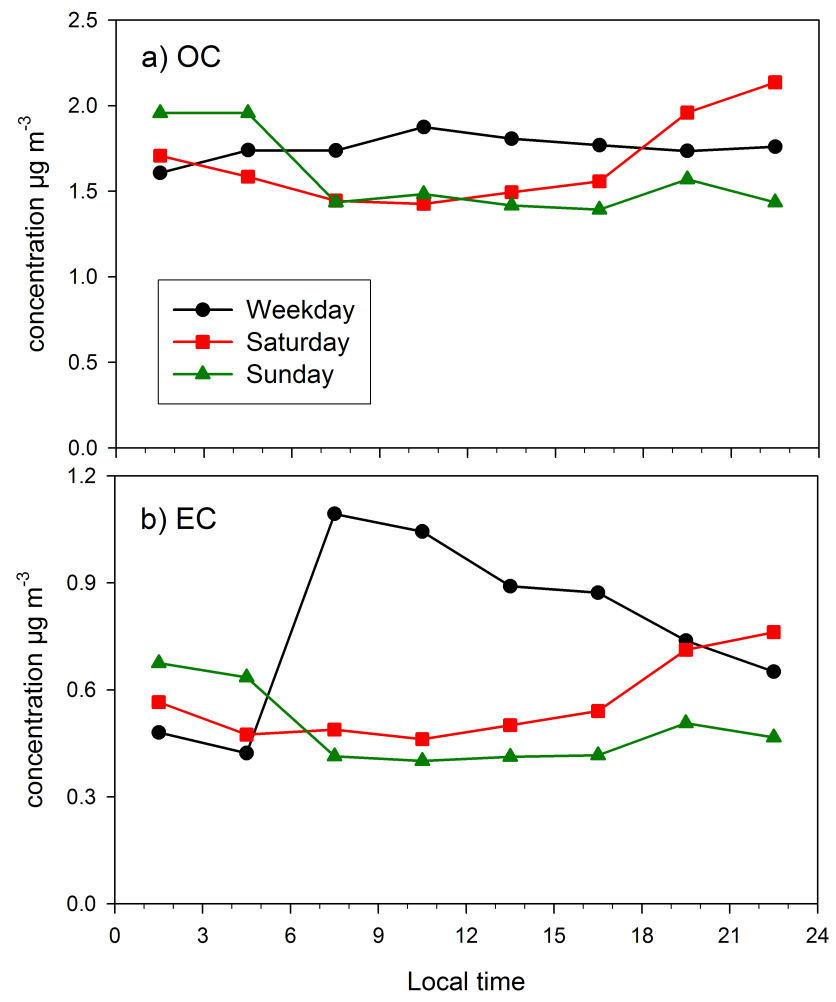

Fig. 7. Diurnal variation of OC (a) and EC (b) concentrations on weekdays, Saturdays and Sundays. Concentrations were measured by the semicontinuous OC/EC analyzer operated from September 2006 to August 2007 with the time-resolution of 3-h.

This kind of atmospheric process is in accordance with the study of Robinson et al., (2006a), in which photochemical oxidation was found to cause severe depletion of hopanes, the molecular markers for motor vehicle emissions, in summer.

\subsection{Online measurements}

\subsubsection{Diurnal variation of OC}

In addition to the $\mathrm{PM}_{1}$ filter samples, the $\mathrm{OC}$ concentration was measured by the semicontinuous OC/EC analyzer with a time-resolution of three hours. In the case of the filter samples the aim was to study the sources of OC on a daily basis, whereas the data from the semicontinuous OC/EC instrument was used to investigate the diurnal variation of the sources. Similar to the filter measurements, semicontinuous OC measurements covered a one year period, from September 2006 to August 2007, but the measurement periods overlapped only for six months. In order to compare the semicontinuous OC/EC to the $\mathrm{PM}_{1}$ filters, the 3-h data were averaged to correspond with the 24-h $\mathrm{PM}_{1}$ filter samples collected simultaneously (September 2006-February 2007; 102 samples). On average, the semicontinuous OC/EC gave $4 \%$ 


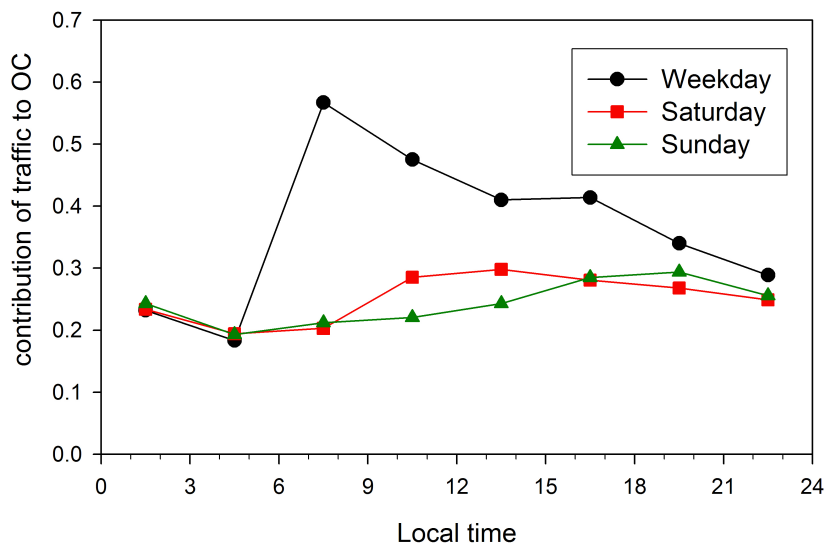

Fig. 8. The contribution of traffic to OC on weekdays, Saturdays and Sundays. Contributions were calculated by using the OC/EC ratio of 0.71 .

larger concentrations for $\mathrm{OC}$ than the $\mathrm{PM}_{1}$ filters $\left(\mathrm{R}^{2} 0.90\right)$. A similar difference was obtained for EC, with $5 \%$ higher concentrations obtained from the semicontinuous OC/EC than from the filter measurements $\left(\mathrm{R}^{2} 0.90\right)$.

The diurnal variation of the $\mathrm{OC}$ concentration was small compared with its day-to-day variability. Even though the OC data was divided into four seasons (fall: SeptemberNovember, winter: December-February, spring: MarchMay, summer: June-August) the diurnal variation was still small. However, there were some typical daily patterns observed in winter and in summer. In winter OC was at its highest in the evening. That can be explained by a low boundary layer height and weak mixing in the evening due to a stable atmosphere. Concerning the emissions of wood combustion, it is most likely that the emissions are highest in the evening when people return to their houses after the work. OC concentrations were especially high on Saturday evenings in wintertime. Besides fireplaces and wood stoves, these high OC concentrations were obviously related to saunas heated typically on Saturday evenings. One example of this kind of local biomass combustion will be shown in Sect. 3.2.3. In Denmark residential wood combustion in the evening has been observed as peak concentrations of EC (Glasius et al., 2006) but that was not observed in Helsinki.

In summer the concentration of OC was slightly lower in the afternoon and in the evening than in other times of the day. Again, this was probably related to the local meteorology resulting from more efficient mixing of afternoon pollutants with increasing temperature in daytime. Semi-volatile organic compounds might also have an effect on the observed trend because the volatilization of these compounds from particles increases with the increasing temperature. In several earlier studies OC has been found to peak in daytime due to SOA formation (e.g. Plaza et al., 2006; Polidori et al., 2006; Takegawa et al., 2006). Even though SOA was found to be a major source for OC in Helsinki in summer (Table 2)

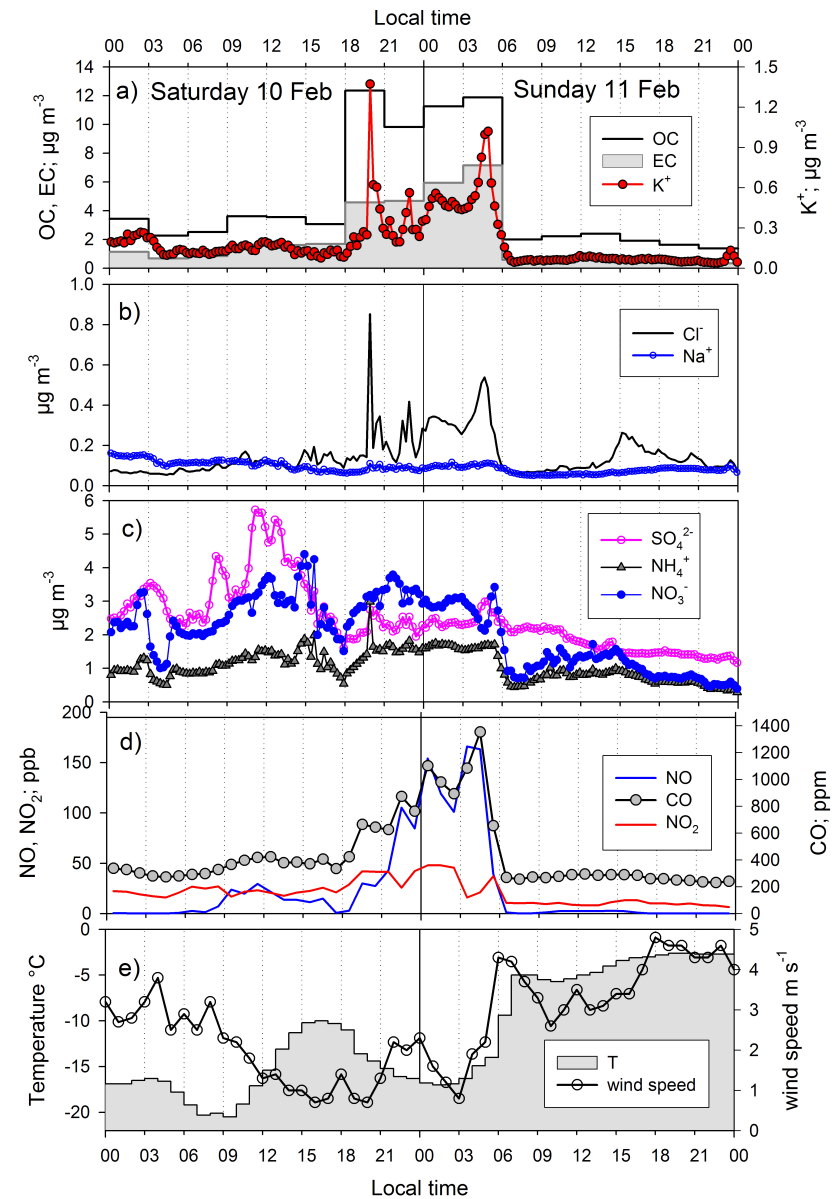

Fig. 9. The concentrations of OC, EC and potassium (a), chloride and sodium (b), sulfate, ammonium and nitrate (c), NO, CO and $\mathrm{NO}_{2}$ (d), as well as temperature and wind speed (e) on 1011 February 2007 in Helsinki. OC and EC concentrations (a) were measured by the semi-continuous OC/EC analyzer and ions $(\mathrm{a}-\mathrm{c})$ by the PILS-IC. Time-resolution was 3 hours for OC and EC and $15 \mathrm{~min}$ for ions. Gaseous components and meteorological parameters are presented as one hour averages.

the formation of SOA could not be seen from the semicontinuous OC data. That indicates the major part of SOA being regional as suggested by Subramanian et al. (2007).

The difference between weekdays and weekends was small for the OC concentrations (Fig. 7a). On average, the $\mathrm{OC}$ concentration was quite stable throughout the day on weekdays, in contrast to clear diurnal variation observed on Saturdays and Sundays. On Saturdays, OC was lower in daytime than at night, but the highest OC concentrations were measured at nights between Saturday and Sunday. In addition to domestic biomass combustion in Saturday evenings the high concentrations were probably caused by traffic. Overall, the OC concentrations were higher on weekdays than on weekends only from 06:00 to 18:00, the difference being in the range $0.30-0.42 \mu \mathrm{g} \mathrm{m}^{-3}$. For EC the diurnal 
variation was close to that of OC on Saturdays and Sundays but on weekdays EC was clearly elevated in daytime because of traffic (Fig. 7b).

\subsubsection{Contribution of traffic to OC}

Because of the low number of chemical components measured online (OC, EC, gases), PMF was not used for the semicontinuous $\mathrm{OC} / \mathrm{EC}$ data. Instead, the impact of traffic on the online OC was estimated by using the OC/EC ratio obtained for traffic by PMF (0.71, Table 2). This approach assumes that all online EC originated from traffic and that the OC/EC ratio for traffic does not depend on the season. On average, this "fixed OC/EC ratio" method gave a larger contribution of traffic to online OC (34\%) than PMF (20\%, Table 2) which was expected since only $58 \%$ of filter-based EC was attributed to traffic by PMF. Also, it should be noted that only half of the measurement period of semicontinuous OC/EC overlapped the period of $\mathrm{PM}_{1}$ filter samples used for PMF. However, the difference between the two methods is reasonable since the main purpose of using this "fixed OC/EC ratio" method was to study the diurnal variation of traffic related OC.

By using the OC/EC ratio of 0.71 the contribution of traffic to OC was $36 \%$ at weekdays and 24 and $25 \%$ on Saturdays and Sundays, respectively (Fig. 8). The contribution of traffic was at its highest at weekdays during morning rush hour, from 06:00 to 09:00, being equal to 57\%. After that the contribution decreased having the lowest value from 03:00 to $06: 00(18 \%)$. On weekends the contribution of traffic to OC ranged from 19 to $30 \%$. On Saturdays the contribution increased slightly in the morning, whereas on Sundays the highest contribution was measured in the evening (18:0021:00) caused obviously by people returning home from their summer cabins. Similarly to the weekdays the lowest contribution on weekends was measured from 03:00-06:00. The contribution of traffic to OC was higher in Helsinki than that measured in Toronto, in May and in June (Brook et al., 2007). In Toronto the contribution of motor vehicles to primary OC was $18 \%$ on weekdays and $7.0 \%$ on weekends. The daytime contribution was 1.5 times that measured during the night in Toronto.

\subsubsection{The influence of biomass combustion (Case study)}

Since neither of the tracers, levoglucosan or potassium, were measured online continuously, the diurnal variation for the contribution of biomass combustion could not be calculated. However, the PILS-IC system operated at SMEAR III in January and February, 2007 enabled studying of the biomass combustion qualitatively. One case of the local biomass combustion is shown in Fig. 9.

On Saturday, 10 February, the OC concentration increased significantly at about 18:00 and remained elevated until 06:00 on Sunday, 11 February. This concentration peak was probably caused by a decreased boundary layer height accompanied by a decreasing temperature and low wind speed (Fig. 9e). In addition to the meteorological situation favoring poor dilution of emissions, there were two major sources for OC on that weekend. The highest OC concentration was measured on Saturday evening at 18:00-21:00 concurrently with the peak concentration of potassium (Fig. 9a). In addition to extensive biomass combustion for domestic heating because of low ambient temperature, the saunas are traditionally heated in Finland on Saturday evening but also the use of a fireplace for pleasure is most common on Saturday evening. In the PILS-IC data the chloride concentration followed closely with that of potassium (Fig. 9b). Since the concentration of sodium was steady on that weekend (Fig. 9b) the increase of chloride was likely to be associated with biomass combustion (Andreae et al., 1998) but it should be noted chloride can also be attributed to coal combustion (Song et al., 2006). In Helsinki the domestic coal combustion can be assumed to be extremely small, and since the coal-fired power plants have high release height they are not likely to affect the chloride concentrations observed near ground level.

Besides biomass combustion the $\mathrm{OC}$ concentration was influenced by traffic. That can be seen from the elevated EC concentrations, especially on Sunday, (Fig. 9a) as well as from $\mathrm{NO}, \mathrm{NO}_{2}$ and $\mathrm{CO}$ concentrations (Fig. 9d). Independent of $\mathrm{NO}$ and $\mathrm{NO}_{2}$, there was a peak in the $\mathrm{CO}$ concentration on Saturday evening (at 19:00-20:00), demonstrating that $\mathrm{CO}$ was attributed to both traffic emissions and local wood combustion as has been observed also by Glasius et al., (2006). Other ions analyzed by the PILS-IC, sulfate, ammonium and nitrate (Fig. 9c), were not influenced by the temperature inversion indicating that they did not originate from the local sources like biomass combustion or traffic.

\section{Summary and conclusions}

The origin of organic carbon in fine particulate matter in Helsinki, Finland, was assessed by measuring the chemical composition of particles with three different timeresolutions. First, the $\mathrm{PM}_{1}$ filter samples were collected on a daily basis for a year and subsequently analyzed for major chemical components and some tracers. The data were analyzed by using PMF which resolved the factors affecting the concentrations. Secondly, the OC and EC concentrations were measured with a time-resolution of three hours by the semicontinuous OC/EC instrument in order to study the diurnal trends of the sources. Finally, one example of the local pollution situation occurring typically in winter was shown. During that case, the PILS-IC determined the concentrations of major ions with the time-resolution of $15 \mathrm{~min}$. 
$\mathrm{PM}_{1}$ filter samples were collected from March 2006 to February 2007. The period was quite special since in spring and summer 2006 large quantities of smoke from biomass burning were transported to Helsinki mostly from Russia. During these episodes the OC concentrations elevated significantly, but the impact of episodes was important also on an annual basis. By taking into account the episodes an annual average for OC was $2.5 \mu \mathrm{g} \mathrm{m}^{-3}$ but it decreased to $1.5 \mu \mathrm{g} \mathrm{m}^{-3}$ when the episodes were excluded. However, since the aim of this study was to evaluate the sources of OC ordinarily affecting Helsinki, the episodes were removed from the data set prior to PMF.

The OC concentrations were found to be influenced by four major sources: biomass combustion, traffic, long-range transport and secondary aerosol production. On an annual basis the OC concentrations were dominated by secondary organic aerosol (34\%). The contribution of SOA was surprisingly high both in winter (16\%) and summer (64\%) when taking into account the low photochemical activity at high latitudes. However, the large SOA fraction can be explained by significant biogenic VOC emissions in the boreal region, serving as precursors for the SOA formation. Biomass combustion constituted the largest fraction of $\mathrm{OC}$ in winter $(41 \%)$, indicating extensive domestic biomass combustion for heating purposes. For traffic the contribution to OC was equal between the fall, winter and spring (25-27\%), but lower in summer (15\%). On average $24 \%$ of OC was from long-range transport into Helsinki. That fraction included probably also long-range transported biomass combustion emissions. Levoglucosan, the tracer used for tracking biomass combustion, may have depleted during the transport.

Traffic influenced OC concentrations throughout the day. By comparing weekdays with weekends, the contribution of traffic was larger between 06:00 and 18:00 on weekdays than on weekends.

Biomass combustion was observed as elevated OC concentrations in the evening in winter, especially on Saturday evenings. Besides wood combustion for domestic heating this finding was related to fireplaces used for pleasure and saunas, both heated traditionally on Saturday evening.

On an annual basis $56 \%$ of OC was water-soluble. All of the four identified sources affected WSOC concentrations but with different contributions than in the case of OC. The contribution of SOA was much larger for WSOC than OC, whereas the influence of traffic was smaller on WSOC than on OC.

Acknowledgements. Sanna Saarikoski thanks the Maj and Tor Nessling Foundation for the financial support. The financial support from the Graduate School in Physics, Chemistry, Biology and Meteorology of Atmospheric Composition and Climate Change (University of Helsinki) and European Union (EUCAARI, Contract No: 036833 ) is also gratefully acknowledged.

Edited by: A. Wiedensohler

\section{References}

Andreae, M. O., Andreae, T. W., Annegarn, H., Beer, J., Cachier, H., le Canut, P., Elbert, W., Meanhaut, W., Salma, I., Wienhold, F. G., and Zenker, T.: Airborne studies of aerosol emissions from savanna fires in southern Africa: 2. Aerosol chemical composition, J. Geophys. Res. Lett., 103, 32 119-32 128, 1998.

Arhami, K., Kuhn, T., Fine, P. M., Delfino, R. J., and Sioutas, C.: Effects of sampling artifacts and operating parameters on the performance of a semicontinuous particulate elemental carbon/organic carbon monitor, Environ. Sci. Technol., 40, 945954, 2006.

Berner, A. and Lürzer, C.: Mass size distributions of traffic aerosols at Vienna, J. Phys. Chem., 84, 2079-2083, 1980.

Birch, M. E. and Cary, R. A.: Elemental carbon-based method for monitoring occupational exposures to particulate diesel exhaust, Aerosol Sci. Tech., 25, 221-241, 1996.

Boman, B. C., Forsberg, A. B., and Järvholm, B. G.: Adverse health effects from ambient air pollution in relation to residential wood combustion in modern society, Scand. J. Work Env. Hea., 29, 251-260, 2003.

Brook, J. R., Graham, L., Charland, J. P., Cheng, Y., Fan, X., Lu, G., Li, S. M., Lillyman, C., MacDonald, P., Caravaggio, G., and MacPhee, J. A.: Investigation of the motor vehicle exhaust contribution to primary fine particle organic carbon in urban air, Atmos. Environ., 41, 119-135, 2007.

Cabada, J. C., Pandis, S., N., and Robinson, A. L.: Sources of atmospheric carbonaceous particulate matter in Pittsburgh, Pennsylvania, JAPCA J. Air Waste Ma., 52, 732-741, 2002.

Chebbi, A. and Carlier, P.: Carboxylic acids in the troposphere, occurrence, sources, and sinks: a review, Atmos. Environ., 24, 4233-4249, 1996.

Decesari, S., Facchini, M. C., Matta E., Lettini, F., Mircea, M., Fuzzi, S., Tagliavini, E., and Putaud, J.-P.: Chemical features and seasonal variation of fine aerosol water-soluble organic compounds in the Po Valley, Italy, Atmos Environ., 35, 3691-3699, 2001.

Dye, C. and Yttri, K. E.: Determination of monosaccharide anhydrides in atmospheric aerosols by use of high-performance liquid chromatography combined with high-resolution mass spectrometry, Anal. Chem., 77, 1853-1858, 2005.

Fine, P. M., Cass, G. R., and Simoneit, B. R. T.: Chemical characterization of fine particle emissions from fireplace combustion of woods grown in the Northeastern United States, Environ. Sci. Technol., 35, 2665-2675, 2001.

Fine, P. M., Cass, G. R., and Simoneit, B. R. T.: Chemical characterization of fine particle emissions from fireplace combustion of woods grown in the Southern United States, Environ. Sci. Technol., 36, 1442-1451, 2002.

Fine, P. M., Cass, G. R., and Simoneit, B. R. T.: Chemical characterization of fine particle emissions from the fireplace combustion of wood types grown in the Midwestern and Western United States, Environ. Eng. Sci., 21, 387-409, 2004.

Fraser, M. P. and Lakshmanan, K.: Using levoglucosan as a molecular marker for the long-range transport of biomass combustion aerosols, Environ. Sci. Technol., 34, 4560-4564, 2000.

Frey, A., Virkkula, A., Saarnio, K., Timonen, H., TolonenKivimäki, O., Aurela, M., Hillamo, R., Tissari, J., Hytönen, K., Willman, P., Jokiniemi, J., Mannila, R., Saari, H., and Näkki, I.: Aerosol composition in fireplace emissions, Report Series in 
Aerosol Science, 83, 325-329, 2006.

Gao, S., Hegg, D. A., Hobbs, P. V., Kirchstetter, T. W., Magi, B. I., and Sadilek, M.: Water-soluble organic components in aerosols associated with savanna fires I southern Africa: Identification, evolution and distribution, J. Geophys. Res., 108, D13, 8491, doi:10.1029/2002JD002324, 2003.

Glasius, M., Ketzel., M., Wåhlin, P., Jensen, B., Mønster, J., Berkowicz, R., and Palmgren, F.: Impact of wood combustion on particle levels in a residential area in Denmark, Atmos. Environ., 40, 7115-7124, 2006.

Hedberg, E., Johansson, C., Johansson, L., Swietlicki, E., and Brorström-Lundén, E.: Is levoglucosan a suitable quantitative tracer for wood burning? Comparison with receptor modeling on trace elements in Lycksele, Sweden, JAPCA J. Air Waste Ma., 56, 1669-78, 2006.

Huang, X.-F., Yu, J. Z., He, L.-Y., and Yuan, Z.: Watersoluble organic carbon and oxalate in aerosols at a coastal urban site in China: Size distribution characteristics, sources and formation mechanisms, J. Geophys. Res., 111, D22212, doi:10.1029/2006JD007408, 2006.

Iinuma, Y., Brügemann, E., Gnauk, T., Müller, K., Andreae, M. O., Helas, G., Parmar, R., and Herrmann, H.: Source characterization of biomass burning particles: the combustion of selected European conifers, African hardwood, savanna grass, and German and Indonesian peat, J. Geophys. Res., 112, D08209, doi:10.1029/2006JD007120, 2007.

Jaffrezo, J.-L., Aymoz, G., Delaval, C., and Cozic J.: Seasonal variation of the water soluble organic carbon mass fraction of aerosol in two valleys of the French Alps, Atmos. Chem. Phys., 5, 28092821, 2005,

http://www.atmos-chem-phys.net/5/2809/2005/.

Karppinen, A., Härkönen, J., Kukkonen, J., Aarnio, P., and Koskentalo, T.: Statistical model for assessing the portion of fine particulate matter transported regionally and long range to urban air, Scand. J. Work Env. Hea., 30 suppl. 2, 47-53, 2004.

Kondo, Y., Miyazaki, Y., Takegawa, N., Miyakawa, T., Weber, R. J., Jimenez, J. L., Zhang, Q., and Worsnop, D. R.: Oxygenated and water-soluble organic aerosols in Tokyo, J. Geophys. Res., 112, D01203, doi:10.1029/2006JD007056, 2007.

Kunzli, N., Kaiser, R., Medina, S., Studnicka, M., Chanel, O., Filiger, P., Herry, M., Horak, F., Puybonnieuax-Texier, V., Quénel, P., Schneider, J., Seethaler, R., Vergnaud, J.-C., and Sommer, H.: Public-health impact of outdoor and traffic-related air pollution: a European assessment, Lancet, 356, 795-801, 2000.

Kuokka, S., Teinilä, K., Saarnio, K., Aurela, M., Sillanpää, M., Hillamo, R., Kerminen, V.-M., Pyy, K., Vartiainen, E., Kulmala, M., Skorokhod, A. I., Elansky, N. F., and Belikov, I. B.: Using a moving measurement platform for determining the chemical composition of atmospheric aerosols between Moscow and Vladivostok, Atmos. Chem. Phys., 7, 4793-4805, 2007, http://www.atmos-chem-phys.net/7/4793/2007/.

Lighty, J. S., Veranth, J. M., and Sarofim, A. F.: Combustion aerosols: factors governing their size and composition and implications to human health, JAPCA J. Air Waste Ma., 50, 15651618, 2000.

Lindfors, V., Laurila, T., Hakola, H., Steinbrecher, R., and Rinne, J.: Modeling speciated terpenoid emissions from the European boreal forest, Atmos. Environ., 34, 4983-4996, 2000.

Loo, B. W. and Cork, C. P.: Development of high efficiency virtual impactor, Aerosol Sci. Tech., 9, 167-170, 1988.

Na, K., Sawant, A. A., Song, C., and Cocker III, D. R.: Primary and secondary carbonaceous species in the atmosphere of Western Riverside County, California, USA, Atmos. Environ., 38, 13451355, 2004.

Naeher, L. P., Brauer, M., Lipsett, M., Zelikoff, J. T., Simpson, C. D., Koenig, J. Q., and Smith, K. R.: Woodsmoke health effects: a review, Inhal. Toxicol., 19, 67-106, 2007.

Nunes, T. V. and Pio, C. A.: Carbonaceous aerosols in industrial and coastal atmospheres, Atmos. Environ., 27A, 1339-1346, 1993.

Orsini, D. A., Ma, Y., Sullivan, A., Sierau, B., Baumann, K., and Weber, R. J.: Refinements to the particle-into-liquid sampler (PILS) for ground and airborne measurements of water soluble aerosol composition, Atmos. Environ., 37, 1243-1259, 2003.

Paatero, P.: Least squares formulation of robust non-negative factor analysis, Chemometr. Intell. Lab., 37, 23-35, 1997.

Paatero P.: The multilinear engine - a table-driven, least squares program for solving multilinear problems, including the n-way parallel factor analysis model, J. Comput. Graph. Stat., 1, 854888, 1999.

Pakkanen, T. A., Loukkola, K., Korhonen, C. H., Aurela, M., Mäkelä, T., Hillamo, R., Aarnio, P., Koskentalo, T., Kousa, A., and Maenhaut, W.: Sources and chemical composition of atmospheric fine and coarse particles in the Helsinki area, Atmos. Environ., 35, 5381-5391, 2001.

Plaza, J., Gómez-Moreno, F. J., Núñez, L., Pujadas, M., and Artínano, B.: Estimation of secondary organic aerosol formation from semi-continuous OC-EC measurements in a Madrid suburban area, Atmos. Environ., 40, 1134-1147, 2006.

Polidori, A., Turpin, B. J., Lim, H.-J., Cabada, J. C., Subramanian, R., Pandis, S., and Robinson, A.: Local and regional secondary organic aerosol: insights from a year of semi-continuous carbon measurements at Pittsburgh, Aerosol Sci. Technol., 40, 861-872, 2006.

Rader D. J. And Marple, V. A.: Effect of ultra-Stokesian drag and particle interception on impaction characteristics, Aerosol Sci. Technol., 4, 141-156, 1985.

Robinson, A. L., Donahue, N. M., and Rogge, W. F.: Photochemical oxidation and changes in molecular composition of organic aerosol in the regional context, J. Geophys. Res., 111, D03302, doi:10.1029/2005JD006265, 2006a.

Robinson, A. L., Subramanian, R., Donahue, N. M., BernardoBricker, A., and Rogge, W. F.: Source apportionment of molecular markers and organic aerosol. 2. Biomass smoke, Environ. Sci. Technol., 40, 7811-7819, 2006 b.

Rogge, W. F., Mazurek, M. A., Hildemann, L. M., Cass, G. R., and Simoneit, B. R. T.: Quantification of urban organic aerosols at molecular level: identification, abundance and seasonal variation, Atmos. Environ., 27A, 1309-1330, 1993.

Ruellan, S. and Cachier, H.: Characterization of fresh particulate vehicular exhausts near a Paris high flow road, Atmos. Environ., 35, 453-468, 2001.

Saarikoski, S., Sillanpää, M., Sofiev, M., Timonen, H., Saarnio, K., Teinilä, K., Karppinen, A., Kukkonen, J., and Hillamo, R.: Chemical composition of aerosols during a major biomass burning episode over northern Europe in spring 2006: Experimental and modeling assessments, Atmos. Environ., 41, 3577-3589, 2007.

Saxena, P. and Hildemann, L. M.: Water-soluble organics in at- 
mospheric particles: a critical review of the literature and application of thermodynamics to identify candidate compounds, J. Atmos. Chem., 24, 57-109, 1996.

Seinfeld, J. H. and Pandis, S. N.: Atmospheric chemistry and physics: From air pollution to climate change, John Wiley, New York, USA, 700-765, 1998.

Sillanpää, M., Frey, A., Hillamo, R., Pennanen, A., and Salonen, R. O.: Organic, elemental and inorganic carbon in particulate matter of six urban environments in Europe, Atmos. Chem. Phys., 5, 2869-2879, 2005,

http://www.atmos-chem-phys.net/5/2869/2005/.

Simoneit, B. R. T., Schauer, J. J., Nolte, C. G., Oros, D. R., Elias, V. O., Fraser, M. P., Rogge, W. F., and Cass, G. R.: Levoglucosan, a tracer for cellulose in biomass burning and atmospheric particles, Atmos. Environ., 33, 173-182, 1999.

Solomon G. M. and Balmes, J. R.: Health effects of diesel exhaust, Clin. Occup. Environ. Med., 3, 61-80, 2003.

Song, Y., Zhang, Y., Xie, S., Zeng, L., Zheng, M., Salmon, L. G., Shao, M., and Slanina, S.: Source apportionment of $\mathrm{PM}_{2.5}$ in Beijing by positive matrix factorization, Atmos. Environ., 40, 1526-1537, 2006.

Subramanian, R., Donahue, N. M., Bernardo-Bricker, A., Rogge, W. F., and Robinson, A. L.: Contribution of motor vehicle emissions to organic carbon and fine particle mass in Pittsburgh, Pennsylvania: Effects of varying source profiles and seasonal trends in ambient marker concentrations, Atmos. Environ., 40, 8002-8019, 2006.

Subramanian, R., Donahue, N. M., Bernardo-Bricker, A., Rogge, W. F., and Robinson, A. L.: Insight into the primary-secondary and regional-local contributions to organic aerosol and $\mathrm{PM}_{2.5}$ mass in Pittsburgh, Pennsylvania, USA, Atmos. Environ., 41, 7414-7433, 2007.

Sullivan, A. P., Peltier, R. E., Brock, C. A., de Gouw, J. A., Holloway, J. S., Warneke, C., Wollny, A. G., and Weber, R. J.: Airborne measurements of carbonaceous aerosol soluble in water over northeastern United States: Method development and an investigation into water-soluble organic carbon sources, J. Geophys. Res., 111, D23S46, doi:10.1029/2006JD007072, 2006.
Szidat, S., Jenk, T. M., Synal, H.-A., Kalberer, M., Wacker, L., Hajdas, I., Kasper-Giebl, A., and Baltensberger, U.: Contributions of fossil fuel, biomass-burning, and biogenic emissions to carbonaceous aerosols in Zurich as traced by ${ }^{14} \mathrm{C}$, J. Geophys. Res., 111, D07206, doi:10.1029/2005JD006590, 2006.

Takegawa, N., Miyakawa, T., Kondo, Y., Jimenez, J. L., Zhang, Q., Worsnop, D. R., and Fukuda, M.: Seasonal and diurnal variations of submicron organic aerosol in Tokyo observed using the Aerodyne aerosol mass spectrometer, J. Geophys. Res., 111, D11206, doi:10.1029/2005JD006515, 2006.

Timonen, H. J., Saarikoski, S. K., Aurela, M. A., Saarnio, K. M., and Hillamo, R. E. J.: Water-soluble organic carbon in urban aerosol: concentrations, size distributions and contribution to particulate matter, Boreal Env. Res., 13, 335-346, 2008.

Tunved, P., Hansson, H.-C., Kerminen, V.-M., Ström, J., Dal Maso, M., Lihavainen, H., Viisanen, Y., Aalto, P. P., Komppula, M., and Kulmala, M.: High natural aerosol loading over boreal forests, Science, 312, 261-263, 2006.

Viana, M., Maenhaut, W., ten Brink, H. M., Chi, X., Weijers, E., Querol, X., Alastuey, A., Mikuška, P., and Večeřa, Z.: Comparative analysis of organic and elemental carbon concentrations in carbonaceous aerosols in three European cities, Atmos. Environ. 41, 5972-5983, 2007.

Viidanoja, J., Sillanpää, M., Laakia, J., Kerminen, V.-M., Hillamo, R., Aarnio, P., and Koskentalo, T.: Organic and black carbon in $\mathrm{PM}_{2.5}$ and $\mathrm{PM}_{10}$ : 1 year of data from urban site in Helsinki, Finland, Atmos. Environ., 36, 3183-3193, 2002.

Weber, R. J., Sullivan, A. P., Peltier, R. E., Russell, A., Yan, B., Zheng, M., de Gouw, J., Warneke, C., Brock, C., Holloway, J. S., Atlas, E. L., and Edgerton, E.: A study of secondary organic aerosol formation in the anthropogenicinfluenced southeastern United States, J. Geophys. Res., 112, D13302, doi:10.1029/2007JD008408, 2007.

Zdráhal, Z., Oliveira, J., Vermeylen, R., Claeys, M., and Maenhaut, $\mathrm{W}$.: Improved method for quantifying levoglucosan and related monosaccharide anhydrides in atmospheric aerosols and application to samples from urban and tropical locations, Environ. Sci. Technol., 36, 747-753, 2002. 